\title{
Induced Systemic Resistance
}

\section{Chaturvedi S* and Paul Khurana SM}

Amity Institute of Biotechnology, Amity University Haryana, India

Editorial

Volume 3 Issue 1

Received Date: July 02, 2018

Published Date: July 06, 2018

DOI: $10.23880 /$ oajmb-16000126

University Haryana, Gurgaon-122413, India, Tel: (+91) 07838931887; Email:

sarika.chaturvedi@gmail.com

\section{Editorial}

About more than 20 years Induced Systemic Resistance the ability of rhizobia, mycorrhizal fungi, plant growth promoting rhizobacteria (PGPR) and plant growth promoting fungi (PGPF) to induce resistance is studied. As plants possess a range of active defense apparatuses that can be actively expressed in response.. Induced systemic resistance (ISR) emerged as an important mechanism by which selected plant growth-promoting bacteria and fungi in the rhizosphere prime the whole plant body for enhanced defense against a broad range of pathogens and insect herbivores [1]. It is activated by biotic and/or abiotic factors. It is dependent on the physical or chemical barrier of the host plant, against pathogens by killing or inhibition of it. Interactions between plants and pathogens can lead either compatible response to a successful infection or incompatible response resistance. It acts through the induction of plant disease resistance to disease prevention and control purposes.

Induced resistance are two types of response (i) local response that occurs in small area of the site originally attacked or infected and (ii) induced resistance or systemic response that is a series of induced plant defense function or in distant, yet unaffected parts [2]. Local response include an oxidative burst which can lead to cell death therefore the pathogen trapped into dead cell by this further spreading is stopped. It also includes changes in cell wall composition and prevents penetration of pathogen. It also causes denove synthesis of antimicrobial compounds as phytoalexins and pathogenesis related proteins.

ISR was demonstrated with different plants, including cucumber, watermelon, muskmelon, tobacco, tomato, green bean, apple and pear, and was found to be effective in these plants against bacterial, fungal, and viral pathogens. e.g. plants as diverse as Arabidopsis thaliana to coffee, and also effective against insects and nematodes (Figure 1).

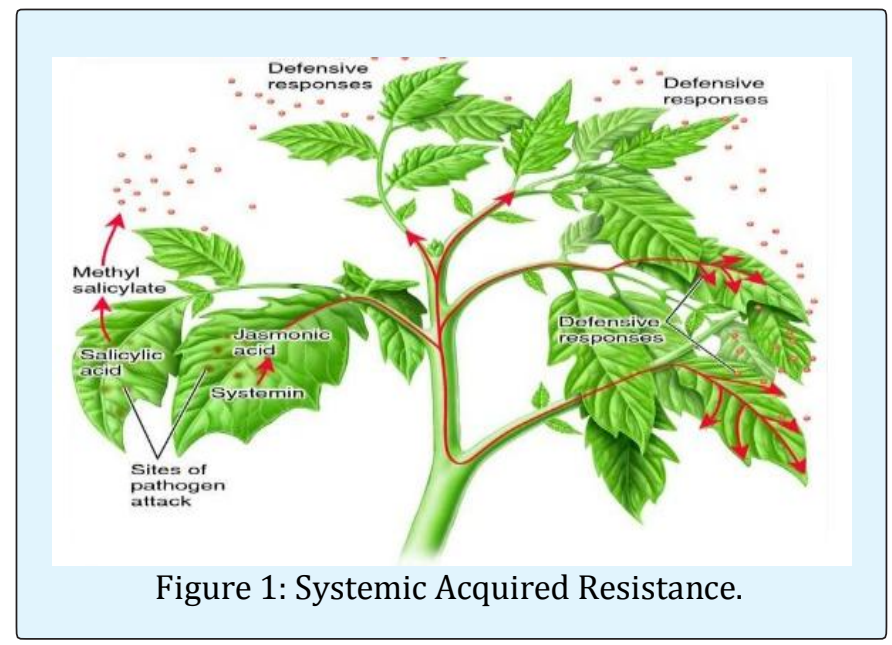

Different factors can induce the disease resistance by abiotic factors and biotic factors. Abiotic factors as physical (mechanical or dry ice damage, electromagnetic, ultraviolet and low temperature and high temperature treatment, etc.) and chemical factors (heavy metal salts, water, salt, salicylic acid, etc). Biotic factors as fungi, bacteria, viruses and their metabolites can induce the plant to the virus, bacteria and fungi and other disease resistance.

Specific Pseudomonas, Bacillus strains induce systemic resistance in viz., carnation, cucumber, radish, tobacco, 
and Arabidopsis, as evidenced by an enhanced defensive capacity upon challenge inoculation [3]. A lot of other plants as melons, tobacco, bean, potato and rice achieved a great success by the induced resistance through biological and chemical factors. Chemical factors or biological factors induced are involved in plant identification of exogenous factors, plant physiological and metabolic changes and plant and pathogen interaction process. The biological factors of plant induced resistance system include mainly plant growthpromoting rhizosphere bacteria (PGPR) or plant growth promoting fungi (PGPF). PGPF can effectively promote plant growth and increase crop yield while causing (or increasing) plant resistance to diseases (sometimes including pests). The use of several PGPR strains was effective at controlling several diseases of cucumber, including anthracnose, angular leaf spot and bacterial wilt localized to plant roots, as a soil drench, transplant mix, root dip, or seed treatment.

Selected strains of plant growth-promoting rhizobacteria (PGPR) suppress diseases by antagonism between the bacteria and soil-borne pathogens as well as by inducing a systemic resistance in plant against both root and foliar pathogens.
Plants possess a range of active defense mechanism that can be actively expressed in response to pathogens and parasites of various scales (ranging from microscopic viruses to phytophagous insect). Induced resistance is a state of enhanced defensive capacity developed by a plant when appropriately stimulated. ISR-inducing PGPR is a useful tool to reduce diseases caused by pathogens.

\section{References}

1. Choudhary DK, Prakash A, Johri BN (2007) Induced systemic resistance (ISR) in plants: mechanism of action. Indian J Microbiol 47(4): 289-297.

2. Vallad GE, Goodman RM (2004) Systemic Acquired Resistance and Induced Systemic Resistance in Conventional Agriculture. Crop Sci 44(6): 1920-1934.

Thomma BPHJ, Eggermont K, Broekaert WF, Cammue BPA (2000) Disease development of several fungi on Arabidopsis can be reduced by treatment with methyl jasmonate. Plant Physiol Biochem 38(5): 421-427.

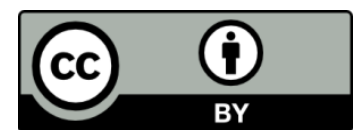

